\title{
TAX PROGRESSIVITY, INCOME DISTRIBUTION AND TAX NON-COMPliANCE
}

Tatiana Damjanovic David Ulph

OXFORD UNIVERSITY CENTRE FOR BUSINESS TAXATION SAÏD BusINESS SCHOOL, PARK END STREET OXFORD OX1 1HP 


\title{
Tax Progressivity, Income Distribution and Tax Non-Compliance.
}

\author{
Tatiana Damjanovic and David Ulph* \\ University of St. Andrews St Salvator's College, KY16 9AL, UK.
}

September 15, 2009

\begin{abstract}
This article examines the determinants of tax non-compliance when we recognise the existence of an imperfectly competitive "tax advice" industry supplying schemes which help taxpayers reduce their tax liability. We apply a traditional industrial organisation framework to model the behaviour of this industry. This tells us that an important factor determining the equilibrium price and hence, the level of noncompliance, is the convexity of the demand schedule. We show that in this context, this convexity is affected by the distribution of pre-tax income, the progressivity of the tax-schedule and the way in which monitoring and penalties vary with income. It is shown that lower pre-tax income inequality as well as a less progressive tax code may cause more tax minimisation activities. Therefore, the frequently advocated policy of reducing the highest tax rate may fail as a policy directed at improving tax discipline. One way of offsetting the possible harm to tax compliance from a less progressive tax could be an adjustment of the penalty and monitoring functions.
\end{abstract}

JEL Classification: $\mathrm{H} 21 ; \mathrm{H} 23 ; \mathrm{H} 26$

Key words: tax compliance, tax administration, inequality, tax progressivity, tax monitoring, penalty function.

*David Ulph is also Senior External Research Fellow, Centre for Business Taxation, University of Oxford. Email addresses: td21@st-andrews.ac.uk, du1@st-andrews.ac.uk 


\section{Introduction}

Tax non-compliance - avoidance and evasion - is a problem of great importance for many countries. For example, the US Internal Revenue Service estimated that about $17 \%$ of due income taxes are not paid (IRS, 2007), while according to the HM-Treasury report (HMRC, 2007), the VAT gap is about $14.2 \%$ in the UK.

Tax non-compliance does not only reduce tax revenue (ceteris paribus) but has a number of other welfare-reducing consequences. ${ }^{1}$

- The loss of tax revenue means that governments either have to spend less on desirable publicly provided goods and services or else are forced to increase the tax burdens on compliant tax payers, thus amplifying the deadweight loss. ${ }^{2}$

- The government's inability to collect sufficient tax revenue may result in a higher deficit and a deterioration of the financial environment. In extreme cases, it may cause financial crises, as in Russia in 1998 and Argentina in 2002.

- Significant amounts of real resources are devoted to both devising tax reducing schemes and to the monitoring and enforcement of tax compliance.

- Non-compliance typically results in otherwise identical taxpayers facing arbitrarily different effective marginal tax rates - which violates a standard condition of efficient taxation and thus increases the distortions of the tax system.

- Since rich individuals are probably more likely to employ avoidance practices, ${ }^{3}$ the government levies heavier taxes on those who are less well-off, which will not only

\footnotetext{
${ }^{1}$ For a detailed overview of the main problems related to tax compliance, see Andreoni, Erard and Feinstein (1998).

${ }^{2}$ Feldstein (1999) estimates the deadweight loss from income tax in the US to be more than twelve times larger than it would have been without tax avoidance.

${ }^{3}$ Lang at al. (1997), which is based on German data, concluded that "the difference between legislative and effective tax rate increases in gross income up to the eight income decile and remains at the maximum difference of about $16 \%$ for the ninth and the tenth decile". See also Agell and Persson (2000) for the avoidance practice within the different income groups in Sweden, while Feinstein (1991) finds a similar relation for TCMP audit findings in 1982 and 1985. Desai, Foley and Hines (2006) and Desai (2005) also indicate that corporate tax avoidance activities are more likely to be undertaken by larger firms.
} 
increase vertical inequality but may slow down the development of small businesses and economic growth.

- It is also important to recognise that non-compliance can have a multiplier effect to the extent that non-compliance by a small group of individuals diminishes the social norm of tax compliance in the wider population of otherwise compliant taxpayers. The importance of such norms has been emphasised in a number of behavioural and experimental studies (Gordon, 1989; Cowell, 1992; Myles and Naylor, 1996; Kim, 2003).

While it is thus important to more fully understand the drivers of tax non-compliance, much of the literature has focused on taxpayer behaviour - the demand side of noncompliance - using either the conventional Allingham-Sandmo model or some other decision-theoretic approach. It is now generally recognised that non-compliance has both a supply side and a demand side, and that more attention needs to be paid to the supply side. Indeed, Joel Slemrod (2004) considers the ignorance of the supply side of tax non-compliance to be a significant shortcoming of traditional economic models, especially in relation to corporate tax behaviour, and points out that the market for tax abusive schemes has grown substantially in recent years. ${ }^{4}$

One aspect of the supply side that has been widely studied is the role of agents/tax preparers who may inform the clients of tax saving opportunities. For example, Erard (1993) shows that the non-compliance on returns prepared by certified public accountant and lawyers is approximately 4.5 times larger than it would have been had their clients prepared their own tax returns. Another aspect focuses on how taxes could be evaded by bribing the tax inspector ${ }^{5}$ or even a member of parliament to issue the right tax

\footnotetext{
${ }^{4}$ The large importance of the disclosure of the tax avoidance schemes has been recognised by HMRC and postulated in Part 7 of the Finance Act 2004. Similarly, the Internal Revenue Service proclaimed that one of its priorities in 2008 is to combat abusive tax avoidance schemes and the individuals who promote them (IRS 2008).

${ }^{5}$ Chander and Wilde (1992) and Hindriks et al (1999) cite different sources and provide outrageous evidence of tax corruption in India, Nepal, Thailand and Taiwan. Hindriks at al (1999), for example, write that surveys in Taiwan "report $94 \%$ of interviewees as having been 'led to' bribe corrupt tax administrators and $80 \%$ of certified public accountants as admitting to bribing tax officials" and "confidential survey as finding that $76 \%$ of all government tax auditors took bribes and $68 \%$ of tax payers had paid
} 
exemption. ${ }^{6}$

In this paper, the focus is on another aspect of supply - the existence of an imperfectly competitive industry that devises and sells tax minimisation schemes. Certainly, in many advanced economies, the market seems to be dominated by a relatively small number of large players. For instance, in the UK, this would be the "Big Four" accountancy firms (KPMG, Ernst and Young, PricewaterhouseCoopers and Deloitte), which often face criticism for the provision of tax shelters for wealthy individuals and business corporations (see, for example, The Financial Times May 10, 2004).

Within such a perspective, a crucial factor determining the amount of non-compliance is the equilibrium price for these schemes. Now, it is well known from the traditional Industrial Organization literature that the equilibrium price depends on certain features of the industry demand curve. For example, Anderson and Régis (2003) show that the more convex is the industry demand function, the lower will be the equilibrium price and the higher the equilibrium quantity. Similarly, Sandmo (1971) and Coes (1977) have shown that the supplier reduces the quantity when facing higher uncertainty/inequality in demand.

The aim of this paper is to explore what factors affect the shape of the demand curve for the tax minimisation industry and hence, the equilibrium price and output. We will investigate how the shape of the demand curve depends on

(i) the progressivity of the tax schedule;

(ii) the level of inequality of the pre-tax distribution of income;

(iii) the shape of penalty and monitoring functions.

A number of important implications will be discussed.

- One of the most important issues is that in a wide class of cases, a greater progressivity of the tax schedule may reduce the supply of tax avoidance/evasion schemes. Conversely, the flatter the schedule, the lower is the equilibrium price of tax min-

bribes". For the tax moral in Latin America, see Torgler (2005).

${ }^{6}$ The harm from legal tax exemption could be very significant for a national tax revenue. For example, according to Åslund (1999), three tax exemptions only cost the Russian federal budget more than 7\% of GDP: the tax grant to the natural gas monopoly company Gazprom at the end of 1993 (2\% of GDP); the secured tax exemptions for the metallurgical industry (2\% of GDP) and the National Sports Fund's right to import alcohol and tobacco without tax (3\% of GDP). 
imisation schemes and hence, the greater is the level of non-compliance. This result is very important because the presumption is often the other way around - the response to avoidance/evasion is to have a very flat schedule (see, for example, Tanzi and Zee, 2000).

- In a wide class of cases, there will be greater tax compliance in economies with a higher level of inequality in pre-tax income.

- Finally, we will show how, given the tax code and pre-tax income distribution, the government can influence the shape of the demand curve for tax evasion and hence, the proportion of non-compliant taxpayers by suitably designing the shape of the monitoring and penalty functions.

The intuition behind these first two results is the following. The more equal are tax duties - which can arise by having either a more progressive tax schedule or a more equal distribution of pre-tax income - the more elastic is demand and thus, the greater is the incentive of suppliers of tax schemes to cut prices to attract a larger share of the population to buy their tax scheme. Conversely, the more unequal are tax duties, the more can be gained by targeting the rich (or those who are ready to pay much more) at a higher price.

We will show that the main results are robust to different assumptions about the nature of market structure.

The rest of the paper is organized as follows. Section 2 presents a general model and characterises the equilibrium price and output of tax reduction schemes. Section 3 derives the main comparative static results and, in particular, the link between tax compliance and both the progressivity of the tax schedule and the degree of income inequality. Section 4 considers two extensions of the previous analysis: first we show how a tax authority can influence the level of compliance through the design of its monitoring and penalty regimes and second we show how the analysis can be generalised to different forms of payment schedules. Section 5 concludes the paper. 


\section{The model}

\subsection{The demand side}

We begin by exploring the demand side of the tax minimization industry and investigate how this is affected by factors such as the distribution of pre-tax income, the tax code, and the shape of the audit probability and penalty functions.

\subsubsection{Individual demand}

There is a continuum of taxpayers that differs in only the pre-tax level, $x$, of some tax base, which could be earned income, profit, bequest etc. We will refer to $x$ as income in the rest of the text. While the income earned by a particular household is private information, we assume the cumulative distribution function of income, $F(x)$, to be common knowledge. For simplicity, we assume that income is distributed over the finite interval $[a, b]$. We assume that $F(x)$ is differentiable and strictly increasing. Let $f(x)=F^{\prime}(x)$ denote the associated density function with $f(x)>0, \forall x \in[a, b]$.

The government determines the tax code, $\tau(x)$, which we take to be exogenous, ${ }^{7} \mathrm{a}$ positive and increasing function relating the level of tax duties to income. For simplicity, we will also assume it to be continuously differentiable.

There is an industry supplying a single tax scheme ${ }^{8}$ that helps taxpayers reduce the amount of tax they pay by some constant proportion $\beta, \beta \in[0,1]$.

However, the particular method of tax reduction may not be perfectly safe, and we assume there to be some probability $\pi, 0 \leq \pi \leq 1$, that the taxpayer will be subjected to audit and, if audited, the scheme will be deemed to constitute tax evasion in which case the taxpayer will have to repay the tax plus a penalty. This interpretation of $\pi$ enables us to encompass a range of possible types of schemes that might be supplied by the market. At one extreme, there is the case considered in most of the existing literature of schemes that are known to constitute pure tax evasion with certainty and, in

\footnotetext{
${ }^{7}$ Roine (2007) and Borck (2006) analyse the property of the affine tax code which results from a voting over redistribution when tax avoidance and evasion are present. Damjanovic (2001) investigated the properties of the optimal tax code design in an economy with a monopolistic tax avoidance provider.

${ }^{8}$ In a related paper, Ulph (2008) analyses the case where the tax advice industry provides a variety of differentiated products ranging from tax planning through avoidance to evasion.
} 
this case, $\pi$ is just the audit probability. At the other extreme, schemes that are known to constitute tax planning or pure tax avoidance with certainty will be perfectly legal and so $\pi=0$, irrespective of the audit probability. More generally, schemes may fall into a grey area where their legality may be a matter of judgement, or may depend on the precise way in which they are implemented and, in this case, $\pi$ will be the product of the audit probability and the probability of being judged to be illegal conditional on being audited. IRS (2008) provides examples of such schemes.

Following Yitzhaki (1972) and Reinganum and Wilde (1986), we assume penalties to be proportional to the tax that is deemed to have been evaded and let $\phi>0$ denote the penalty per unit of tax evaded. Consequently, compared to the outcome under compliance, purchasing the scheme will increase disposable income by $\beta \tau(x)$ if the taxpayer is not deemed to be evading tax, but will reduce it by $\phi \beta \tau(x)$ if the taxpayer is deemed to be evading tax. Assuming that taxpayers are risk neutral, the expected value of purchasing a scheme will be $\alpha \tau(x)$, where $\alpha=\beta(1-\pi(1+\phi))$. Obviously, we need to assume that $\alpha>0$ to ensure that any scheme is purchased. Given the low coverage rates (audit probabilities) operated by most tax authorities, this is an innocuous assumption.

In summary, there is thus a single type of scheme available and its properties are summarised by parameter $\alpha$, giving the expected net percentage reduction in tax through purchasing a scheme. ${ }^{9}$

For the moment, we will assume that the scheme being sold is a generic/off-the-peg scheme that could be purchased and implemented by any taxpayer. In this case, the seller of the scheme will know nothing about the characteristics of the purchaser and, in particular, his income, $x$, and cannot charge different prices for different taxpayers i.e. engage in price discrimination. In Section 4.2 we will consider the alternative case where sellers provide a bespoke service through which they learn the taxpayer's income and thus can offer a schedule of prices that varies with income.

Thus, let us assume for the moment that sellers of this scheme are unable to observe the individual incomes of the taxpayers who buy them. Therefore, schemes will be sold on the market at a common price $p>0$ which takes the form of an up-front fee. Clearly,

\footnotetext{
${ }^{9}$ So far, we have assumed $\alpha$ to be independent of income. In section 4 , this assumption will be relaxed, and we will investigate how equilibrium tax compliance depends on the progressivity of the tax evasion technology, $\beta(x)$; the audit probability, $p(x)$; and the penalty function, $\phi(x)$.
} 
they will only be bought by those taxpayers with an income above the critical threshold $\underline{x}(p)$ defined by

$$
\alpha \tau(\underline{x}(p))=p
$$

\subsubsection{Aggregate Demand}

It follows from (1) that when the price is $p$, the fraction of taxpayers who buy the scheme - i.e. aggregate demand - will be

$$
Q=1-F[\underline{x}(p)], \quad 0 \leq Q \leq 1
$$

As is common, it useful to work with the inverse aggregate demand function. So, let $\underline{x}(Q)$ be the critical level of income above which taxpayers will have to buy a scheme in order to give rise to aggregate demand, $Q$. Then, $\underline{x}(Q)$ is implicitly defined by

$$
Q \equiv 1-F[\underline{x}(Q)], \quad 0 \leq Q \leq 1
$$

and so

$$
\underline{x}^{\prime}(Q)=-\frac{1}{f(\underline{x}(Q))} .
$$

Consequently, the inverse aggregate demand function is

$$
p(Q) \equiv \alpha \tau(\underline{x}(Q))
$$

with

$$
p^{\prime}(Q)=-\frac{\alpha \tau^{\prime}(\underline{x})}{f(\underline{x})}<0 .
$$

\subsection{Supply Side}

As indicated in the introduction, we will assume that the tax advice industry is best described as an imperfectly competitive oligopoly, comprising a small number of large firms.

There are $n \geq 1$ identical firms supplying the given type of scheme.

The tax minimization industry could be compared with the research and development sector. To provide an effective tax reduction scheme, suppliers must conduct complex research into local and international tax law, devise a scheme and then "test" it by seeking a legal opinion as to whether it works in law. Since, by assumption, we are dealing with 
marketed rather than bespoke schemes, once devised, the marginal cost of producing an additional version of the scheme is pretty minimal. ${ }^{10}$

Accordingly, we assume that any given firm has a technology represented by the cost function

$$
\gamma(q)=C+c q
$$

where $C$ is the fixed cost and $c$ is the marginal cost.

To have an interesting story, we assume that the marginal costs are sufficiently low so that, if schemes were available at a price equal to the marginal cost, some consumers would be willing to buy them. Formally, we assume there to exist a level of income $\underline{\underline{x}}$, $a<\underline{\underline{x}}<b$, such that

$$
\alpha \tau(\underline{\underline{x}})=c .
$$

Notice that $\underline{\underline{x}}$ is the minimum level of income above which individuals would purchase a scheme if the tax advice industry were perfectly competitive.

For later purposes, it will be helpful to re-write (7) as

$$
\tau(\underline{\underline{x}})=k=\frac{c}{\alpha}
$$

where $k$ is the ratio of distribution costs to the expected benefit of acquiring a scheme and can be considered as measuring the effectiveness of the tax supply industry.

In the case where the supply industry is imperfectly competitive, we assume that firms compete in quantities, let $q$ be the output chosen by a typical firm and $q^{-}$denote the output of all other firms - so that aggregate output is $Q=q+q^{-}$.

We do not assume a particular form of competition in the market. Rather, we adopt a conjectural variation approach ${ }^{11}$ whereby each firm assumes that if it increases output

\footnotetext{
${ }^{10}$ Remember that we can have the same model allowing the cost to vary with the tax duties of the customer, with the assumption that this cost will be transferred to the tax avoider ex post.

${ }^{11}$ The concept of conjectural variation was introduced by Bowley (1924) and since then, it has been used by economists to explain more diversified market outcomes rather than restricted Nash equilibrium prices or outputs. To narrow down its too broad and arbitrary predictions, many researchers have focused on the rationality and consistency of conjectural variation (see Laitner, 1980; Bresnahan 1981; Kamien and Schwartz, 1983; Robson, 1983; Ulph 1983). Despite theoretical objections to the concept, empirical evidence provides widespread support for the phenomenon (see Iwata, 1974; Appelbaum 1979; Just and Chern, 1980; Kolstad and Wolak, 1986). Then, a natural question arises: how does conjectural variation
} 
by one unit, the total output of all remaining firms will change by the amount $\psi,{ }^{12}$ that is

$$
\frac{d q^{-}}{d q}=-\psi, \quad 0 \leq \psi<1
$$

Cournot competition arises when $\psi=0$ and perfect/Bertrand competition when $\psi=1$. Notice, however, that we are excluding the uninteresting Bertrand equilibrium, where the price would just be driven down to the marginal cost and no firm would make a profit.

From (5) and (6), the profits made by a typical firm are

$$
\Pi\left(q, q^{-}\right)=q p(Q)-C-c q
$$

From (9) and (10), it follows that the equilibrium fraction of taxpayers who purchase a scheme, $Q^{e}$, is characterised by

$$
\left(p\left(Q^{e}\right)-c\right)+\frac{1}{\chi} Q^{e} p^{\prime}\left(Q^{e}\right)=0
$$

where $\chi=\frac{n}{1-\psi} \geq 1$ measures the competitiveness of the industry.

In what follows, we assume that we have a non-trivial equilibrium in which $Q^{e}>0$, so there are some non-compliant taxpayers and the equilibrium price of a scheme is above the marginal cost.

Equation (11) is the standard result, characterising the equilibrium of a homogenous good oligopoly.

The equilibrium will depend on three factors: marginal costs, $c$; competitiveness of the industry, $\chi$; and the nature of the demand schedule. Indeed, we know from Anderson and Regis (2003) that the equilibrium will depend on the convexity of the aggregate demand function.

From (4), we can see that the aggregate demand schedule in turn depends on the nature of both the tax schedule and the distribution of income. To more clearly bring out how these underlying factors influence the equilibrium, substitute (2), (4), (5) into affect market performance? Anderson (1977), Kamien and Schwartz (1983) and Kolstad and Wolak (1986) found that higher conjectural variation leads to lower output and higher prices.

${ }^{12}$ In the special case of monopoly, where $n=1$ and there are no other firms, we make the natural assumption that $\psi=0$. 
(11), and then, after some rearrangements, we can also see that the equilibrium cut-off level of income above which taxpayers purchase a scheme, $\underline{x}^{e}$, is characterised by

$$
\tau\left(\underline{x}^{e}\right)=k+\frac{1}{\chi} \tau^{\prime}\left(\underline{x}^{e}\right) \frac{1-F\left(\underline{x}^{e}\right)^{\prime}}{f\left(\underline{x}^{e}\right)} .
$$

From (7), (12) and our assumption that $Q^{e}>0$, it follows that $\alpha \tau\left(\underline{x}^{e}\right)>c$, and that $\underline{\underline{x}} \leq \underline{x}^{e}<b$, with $\underline{x}^{e}=\underline{\underline{x}}$ in a special case of perfect/Bertrand competition.

To derive comparative static results, it is useful to establish an alternative way of characterising the equilibrium. Accordingly, let us define the function

$$
H(x)=(\tau(x)-k)^{1 / \chi}[1-F(x)]
$$

Proposition 1 There exists a unique $\underline{x}^{e}$, which solves (12) such that $\underline{x}^{e}=\max (\arg \max H(x))$. Moreover, $a<\underline{x}^{e}<b$ and therefore $H\left(\underline{x}^{e}\right)>0 .{ }^{13}$

Proposition 1 defines the equilibrium threshold income which splits the population into fully compliant taxpayers and non-compliant taxpayers who use a tax minimisation scheme and, consequently, though equation (2) the proportion, $Q$, of the taxpayer population that is non-compliant.

$Q$ provides one measure of the amount of non-compliance in the economy.

Another measure of non-compliance is the tax gap - the amount of uncollected tax. This can, in gross terms, be defined as the amount of tax that taxpayers initially try not to pay and, once more expressed in absolute terms, this would be

$$
G_{\text {gross }}=(1-\beta) \int_{\underline{x}}^{b} \tau(x) f(x) d x .
$$

Alternatively, the tax gap can be defined in net terms as the amount of tax that taxpayers ultimately succeed in not paying after the effects of audit and repayment are taken into account and, once more expressed in absolute terms, this would be

$$
G_{n e t}=(1-\pi)(1-\beta) \int_{\underline{x}}^{b} \tau(x) f(x) d x .
$$

\footnotetext{
${ }^{13}$ In general, there could be infimum solutions to problem (12) and they will all belong to arg max $H(x)$. However, we restrict our attention to the solution that is most preferable to the government, $\underline{x}^{e}=$ $\max (\arg \max H(x))$.
} 
Each of these can also be measured in relative terms as a fraction of the total amount of tax that would have been collected had all taxpayers been fully compliant.

Whatever measure is used, factors such as the risk of being found to be non-compliant, $\pi$, the shape of the tax schedule $\tau(x)$ and the distribution of income $f(x)$ will affect the tax gap through two channels:

- there is the direct impact, treating $\underline{x}$ as constant;

- there is an indirect or behavioural effect that works through the impact of these factors on $\underline{x}$.

In all that follows, we want to purely focus on these indirect or behavioural effects and, consequently, on changes in the value of $\underline{x}$. So, although we will establish a series of comparative static propositions about the effects of various parameter changes on the number of non-compliant taxpayers, these also tell us about the qualitative indirect effects of these changes on the tax gap. ${ }^{14}$

Remark 1 From (13), it follows that there are five factors that will generate comparative static effects:

- the marginal cost per client, $c$;

- the efficiency of the tax saving scheme, $\alpha$;

- the competitiveness of the tax advice industry, $\chi$;

- the nature of the tax schedule, $\tau(x)$;

- the nature of the distribution of income, $f(x)$.

In the next section, we establish the comparative static results relating to all these five factors.

\footnotetext{
${ }^{14}$ The behavioural effect is of great importance per se. A low tax discipline reduces the effectiveness of tax audit, increases the costs of tax enforcement and, as mentioned before, undermines the social norms of tax compliance. It may even stimulate strategic tax con-compliance as discussed in Bassetto and Phelan (2008).
} 


\section{Comparative Static Results}

\subsection{General discussion}

In this section, we establish the main comparative static results of the paper. We will make repeated use of the following Proposition:

Proposition 2 Suppose that $\widetilde{H}(x)=H(x) g(x)$, where $g(x)$ is positive, continuously differentiable and $g^{\prime}(x)>0$, then for the corresponding pair $\underline{\widetilde{x}}^{e}, \underline{x}^{e}$ defined as in Proposition 1, it follows that $\underline{\widetilde{x}}^{e}>\underline{x}^{e}$ and so, $\widetilde{Q}^{e}<Q^{e}$.

In the rest of the paper, we will investigate how the change of one of the factors described in Remark 1 will affect the function $H(x)$ and the proportion of honest taxpayers.

In particular, we would like to establish how changes in the tax code or in the underlying distribution of income that will affect the distribution of the tax burden affect the proportion of non-compliant taxpayers. For this purpose, we would like to relate the monotonicity of the function $g(x)=\widetilde{H}(x) / H(x)$ introduced in Proposition 2 to the Lorenz dominance criterion for the distribution of incomes.

Lorenz dominance, introduced in Atkinson (1970), is one of the most popular orderings of inequality. Atkinson demonstrated that if the Lorenz curve (which shows the proportion of total income received by the poorest $t \%$ of the population) for one distribution lies below the Lorenz curve associated with another, inequality in the first case is higher for a wide class of inequality measures.

Naturally, it is somewhat cumbersome to construct the Lorenz curve every time we need to compare the inequality resulting from different income distributions. So, we need a test whereby we can guarantee that one income distribution Lorenz dominates another without having to compute the associated Lorenz curves. Now, one way of reducing inequality is to carry out a progressive redistribution. That is, if we transform income in such a way that the rate of increase in income is smaller for a richer than for a poorer person, the new Lorenz curve will lie above the old one and the two Lorenz curves do not intersect.

This idea is formalised in the following Lemma which was proved in Kakwani (1977) and Jakobsson (1976) for a continuous domain and differentiable income transformation, 
and in Keen, Papapanagos and Shorrocks (2000) for a discrete income distribution. For proof in a more general set-up, see Le Breton, Moyes and Trannoy (1996) or Damjanovic (2005), which provides a simpler proof.

Lemma 1 Let $y(x)$ and $z(x)$ be a positive non-decreasing function transforming income $x$. Then, $y(x)$ is more equally distributed than $z(x)$ iff $\frac{y(x)}{z(x)}$ is a decreasing function.

Lemma 1 and Proposition 2 provide the basis for showing the conceptual relation between distributional inequality, the function $H(x)$ and hence, the equilibrium amount of tax non-compliance. We spell this out in the rest of the section.

\subsection{Higher Marginal Costs and Lower Net Benefit}

There are many factors that can cause the marginal costs of providing schemes to vary. Like any technology, this will be subject to technical progress and knowledge spillover. For example, ideas developed in the US for lowering tax may, with some adaptation, be applicable to the UK. On the other hand, we could envisage a tax authority introducing legislation such as disclosure powers, which make it more difficult for the tax advice industry to market effective schemes. This could show up as an increase in the marginal costs of distributing a scheme, $c$, since it may require more effort to fine-tune the scheme to each customer's circumstances.

Clearly, there is a number of steps that a tax authority can take to increase the risk of successful challenge, $\pi$, and the penalty on evasion $\phi$, both of which will reduce the net benefit of a scheme, $\alpha$.

Both increases in marginal costs, $c$, and reductions in the net benefit, $\alpha$, will show up as an increase in costs relative to benefit $k=\frac{c}{\alpha}$ and, intuitively, this will result in a higher equilibrium price for schemes and, consequently, a higher critical income threshold above which schemes are bought, $\underline{x}^{e}$, and thus, a smaller number of non-compliant taxpayers. Formally, we have:

Proposition 3 If $\widetilde{k}>k$ then $\underline{\widetilde{x}}^{e}>\underline{x}^{e}$ and so $\widetilde{Q}^{e}<Q^{e}$.

Proof. $\quad \widetilde{H}(x)=[\tau(x)-\widetilde{k}]^{1 / \chi}[1-F(x)]=g(x) H(x)$ where $g(x)=\left[\frac{\tau(x)-\widetilde{k}}{\tau(x)-k}\right]^{1 / \chi}$. It is easily seen that $g(x)$ is a strictly increasing function and the result follows from Proposition 2. 


\subsection{Increased competition}

Our model of competition is very general and nests as special cases:

- Monopoly: $n=1, \psi=0$;

- Cournot oligopoly: $n>1, \psi=0$;

- Bertrand equilibrium (approximately): $n>1, \psi \approx 1$;

Therefore, it is interesting to ask how the equilibrium is affected when there is an increased degree of competition in the sense of either an increase in the number of firms, $n$, serving the market, or an increase in the intensity of price competition, $\psi$. These will both have the effect of increasing the parameter $\chi=\frac{n}{1-\psi}$ and, as in conventional models of oligopoly, these will drive down the equilibrium price and expand equilibrium output, thus leading to less compliance. ${ }^{15}$ This is confirmed in the following Proposition:

Proposition 4 If the industry supplying tax advice becomes more competitive, the proportion of non-compliant taxpayers will increase. Formally, if $\widetilde{\chi}>\chi$ then $\underline{\widetilde{x}}^{e}<\underline{x}^{e}$ and so $\widetilde{Q}^{e}>Q^{e}$.

Proof. $\widetilde{H}(x)=H(x) g(x)$ where $g(x)=(\tau(x)-k)^{\frac{1}{\tilde{\chi}}-\frac{1}{\chi}}$. It is easily seen that $g^{\prime}(x)<0$ and the result follows from Proposition 2.

\subsection{Tax Progressivity and Compliance}

In this section, we establish a link between the progressivity of the tax schedule, $\tau(x)$, and the proportion of taxpayers who are non-compliant.

\footnotetext{
${ }^{15}$ Now, a particular interpretation of our model is one in which corrupt tax organisations or officials offer tax grants and exemptions for particular firms in return for a bribe, with the case of a monopolistic corrupt official being similar to that described in Shleifer and Vishny (1993). Proposition 3 shows that to increase compliance, the government should reduce the degree of competition in the tax minimizing industry. For example, the right to issue tax grants and tax exemptions should only be given to one authority. Our prescriptions are the opposite of those in Shleifer and Vishny (1993). This is because Shleifer and Vishny's paper addresses the situation where bureaucrats are bribed to provide some socially valuable goods, whilst we are investigating the production of tax avoidance, which is a "social bad".
} 
Now, one weak sense of progressivity relates to how unequally the tax burden is distributed. At one extreme, a poll tax makes everyone pay the same amount of tax while, under a progressive tax system, the rich pay more tax than the poor. We capture this idea through the following definition.

Definition 1 We will say that the tax duties $\widetilde{\tau}$ are less equally distributed than $\tau$ if $\left[\frac{\widetilde{\tau}(x)}{\tau(x)}\right]^{\prime}>0$.

Definition 1 is consistent with the Lorenz dominance criterion for the distribution of tax duties, as discussed in Section 3.1.

The first and most general proposition we can establish that connects the shape of the tax schedule to the level of compliance relates to the distribution of the profits made by tax advisers from different taxpayers: $\alpha(\tau(x)-k)$.

Definition 2 We will say that the tax code $\widetilde{\tau}$ results in a less equally distributed tax adviser profit than $\tau$ if $g^{\prime}(x)>0$ where $g(x)=\left[\frac{\widetilde{\tau}(x)-k}{\tau(x)-k}\right]$.

Then, we have the following proposition:

Proposition 5 Let $\left[\frac{\widetilde{\tau}(x)-k}{\tau(x)-k}\right]^{\prime}$ be positive so that $\underline{\widetilde{x}}^{e}>\underline{x}^{e}$ and so that $\widetilde{Q}^{e}<Q^{e}$.

This is an immediate corollary of Proposition 2.

For the interesting case where all costs of producing a tax scheme are purely the fixed costs of "R\&D" and the marginal cost of distributing the scheme is zero - so that $c=k=0$ - there is an immediate link between the distribution of tax adviser profits and the distribution of tax burdens, namely progressivity.

The following proposition shows that in this case, the proportion of compliant tax payers is higher when the tax duties are less equally distributed.

Corollary 1 Let $\left[\frac{\widetilde{\tau}(x)}{\tau(x)}\right]^{\prime}$ be positive and assume that the per client cost is zero, $k=0$, then $\underline{\widetilde{x}}^{e}>\underline{x}^{e}$ and so $\widetilde{Q}^{e}<Q^{e}$. 
The intuition is the following. The move to a more progressive tax system will raise the average tax rate - and hence the willingness to pay for a scheme - of supra marginal consumers. The industry will accordingly increase profits by increasing the price of tax schemes and catering more for high demand consumers - thus reducing the number of schemes sold.

Remark 2 As noted above, it follows that having less equally distributed tax revenues will reduce the tax gap through the indirect effect. Naturally, it does not follow from this proposition that the overall effect on the tax gap will be negative. Although there are fewer non-compliant taxpayers, these will typically be liable for a larger amount of tax, so the total amount of tax underpaid could either rise or fall.

So far, we have considered very general tax codes $\widetilde{\tau}(x)$ and $\tau(x)$ but we have been able to get sharp propositions relating their relative progressivity to the levels of compliance they induce only in the case where the marginal costs are zero. When the marginal costs are positive, Proposition 5 still allows us to establish an important link between tax progressivity and tax compliance, provided that we confine ourselves to affine transformations of tax codes and provided that the increase in progressivity is sufficiently high.

Definition 3 The tax code $\widetilde{\tau}(x)$ is a progressive affine transformation of the tax code $\tau(x)$ if $\widetilde{\tau}(x)=\mu \tau(x)-s$, where $s>0, \mu>1$.

Proposition 6 A progressive affine transformation of the tax code reduces the proportion of non-compliant tax payers $\left(\widetilde{Q}^{e}<Q^{e}\right)$ iff $\frac{s}{\mu-1}>k$.

Corollary 2 If $\widetilde{\tau}(x)=\mu \tau(x)-s$, where $s>0, \mu>1$, it is easily shown that $\left[\frac{\widetilde{\tau}(x)-k}{\tau(x)-k}\right]^{\prime}=$ $\frac{\tau^{\prime}(x)(\mu-1)}{(\tau(x)-k)^{2}}\left(\frac{s}{\mu-1}-k\right)>0$. The result follows from Proposition 2.

Proposition 6 shows that an increase in tax progressivity could improve the tax discipline. As in the above remark, this does not necessarily imply an increase in the tax gap.

The reason for having to ensure that the increase in progressivity is sufficiently large is as follows. In general, the ratio of tax adviser profits under the two tax codes can be 
represented as $\left[\frac{\widetilde{\tau}(x)-k}{\tau(x)-k}\right]=\frac{\widetilde{\tau}(x)-k}{\widetilde{\tau}(x)} \frac{\widetilde{\tau}(x)}{\tau(x)} \frac{\tau(x)}{\tau(x)-k}$. If $k>0$ the first term is strictly increasing in $x$ and, following Definition 1 , so is the second term provided that the tax code $\widetilde{\tau}(x)$ is more progressive than $\tau(x)$ - i.e. produces more unequal tax burdens. However, if $k>0$, the third term is strictly decreasing in $x$. To ensure that tax adviser profits are more unequally distributed, we have to ensure that the increase in progressivity of the tax code as reflected in $\frac{s}{\mu-1}$ is high relative to $k$.

So far, we have compared the levels of compliance under two tax codes that differ in their degree of progressivity, but we have made no assumptions about the amount of tax raised under these two schedules. However, often in comparing tax codes we do so under the assumption of revenue neutrality - i.e. that they raise the same amount of tax, or at least would do so if all taxpayers were fully compliant. Assume now that the government carries out an affine tax reform which, if all tax-payers were fully compliant, would be revenue neutral and would result in a more progressive tax schedule: a higher marginal tax rate, lower taxes for the poor and higher taxes for the rich. So $\widetilde{\tau}(x)=\mu \tau(x)-s$, $\mu>1, s>0$ and

$$
\bar{\tau}:=\int_{a}^{b} \widetilde{\tau}(x) f(x) d x=\int_{a}^{b} \tau(x) f(x) d x,
$$

where $\bar{\tau}$ is the average amount of tax that would be raised in the case of full compliance. Condition (14) would imply that $s=(\mu-1) \bar{\tau}$. Therefore, in this case $g^{\prime}(x)=\left[\frac{\widetilde{\tau}(x)-k}{\tau(x)-k}\right]^{\prime}=$ $(\mu-1) \frac{\tau^{\prime}(x)}{(\tau(x)-k)^{2}}(\bar{\tau}-k)$ which is positive if and only if $\bar{\tau}>k=\tau(\underline{\underline{x}})$. This latter result requires that the average benefit from tax non compliance exceeds the marginal cost of supply or, equivalently, that the individual with average tax duties would be involved in tax non-compliance should the tax avoidance market be perfectly competitive. We formulate this result in Proposition 7.

Proposition 7 The move to a more progressive tax system will reduce the proportion of non-compliant taxpayers if, had the industry supplying tax advice been perfectly competitive, the minimum level of income above which all taxpayers are non-compliant is below the income of the individual with average tax duties. Formally, the result is:

$$
\underline{\widetilde{x}}^{e} \gtrless \underline{x}^{e} \quad \text { as } \quad \tau(\underline{\underline{x}}) \lessgtr \bar{\tau} \text {. }
$$

NOTE 1: Another way of stating this result is to say that the impact of an increase in tax progressivity on tax discipline depends on how high is the marginal cost of distributing 
the tax scheme, $c$, in relation to the benefit that a taxpayer paying the average amount of tax will obtain from acquiring a scheme to reduce taxes. If the cost is not very high, $c<\alpha \bar{\tau}$, then a revenue-neutral tax reform that makes the tax system more progressive will result in better tax discipline - fewer people engaging in non-compliance.

NOTE 2: Although the condition for the conclusion to hold refers to the critical threshold level of income when the supply industry is perfectly competitive, the result holds for any degree of competitiveness.

One implication of this remark is that if the industry is imperfectly competitive, it will not always be possible to tell whether the condition of the theorem holds just by using observations on which taxpayers are actually non-compliant in the given situation. However, one case where we can say something more definite is as follows:

Corollary 3 If there are non-compliant taxpayers with below-average tax duties then the move to a more progressive tax system will reduce the proportion of non-compliant taxpayers. Formally, if $\tau\left(\underline{x}^{e}\right)<\bar{\tau}$ then $\underline{\tilde{x}}^{e}>\underline{x}^{e}$.

Proof. Since $\tau(\underline{\underline{x}})<\tau\left(\underline{x}^{e}\right)$ it follows that if $\tau\left(\underline{x}^{e}\right)<\bar{\tau}$ then $\tau(\underline{\underline{x}})<\bar{\tau}$ and the conclusion follows from Proposition.7

NOTE 3 If the assumption of Corollary 3 holds and the marginal cost is high, an increase in progressivity will tend to increase non-compliance both in the sense that the proportion of non-compliant taxpayers increases and that the total underpayment of taxes - the tax gap - will increase.

To conclude this subsection, note that the conclusions of both Proposition 6 and Proposition 7 question the widely held belief that moving towards a flatter, less progressive tax code will reduce the amount of non-compliance. Thus, a reduction in the marginal tax rate for the highest tax bracket is often recommended as a means of reducing the incentives for tax avoidance and evasion (see, for example, Tanzi and Zee, 2000). However, the present model illustrates that this policy may result in the completely opposite outcome, ${ }^{16}$ in the case where the marginal cost per client of supplying a scheme is relatively small.

\footnotetext{
${ }^{16}$ Indeed, exactly such an outcome was reported in Russia in 2002. Starting from 2001, the Russian government cut the profit tax rate from 35 to 25 percent and broadened the tax base by revoking investment preferences, which made the tax duties more equally distributed. By implementing this measure, the Russian government intended to reduce the incentives for tax avoidance and tax evasion.
} 


\subsection{Income Inequality and Compliance}

In this section, we will show that in a wide class of cases, a more equal distribution of the tax base may be associated with a higher rate of tax non-compliance.

Consider two different distributions of income on the interval $[a, b]$ with the cumulative distribution functions $F(x)$ and $\widetilde{F}(x)$. Let us also define the survival probability ratio of these two distributions as $g(x)=\frac{1-\widetilde{F}(x)}{1-F(x)}$. From Proposition 2, we immediately get the following result:

Proposition 8 Consider the survival probability ratio $g(x)=\frac{1-\widetilde{F}(x)}{1-F(x)}$. If $g^{\prime}(x)>0$, then for any tax code $\tau(x)$, the income distribution $F(x)$ will imply a higher level of tax noncompliance than $\widetilde{F}(x)$, i.e. $Q^{e}>\widetilde{Q}^{e}$.

Proof. Propositions 1 and 2 immediately give us the sufficient condition for increasing the indirect effect of tax non-compliance.

To relate this proposition to income inequality, let $h(x)=f(x) /[1-F(x)]$ and $\widetilde{h}(x)=$ $\widetilde{f}(x) /[1-\widetilde{F}(x)]$ be the hazard rates associated with the two distributions. Now, it is immediately obvious that $g^{\prime}(x)=g(x)[h(x)-\widetilde{h}(x)]$ and thus, $g(x)$ has a positive first derivative if and only if, for all $x$, the distribution $F(x)$ has a higher hazard rate than the distribution $\widetilde{F}(x)$. We say that in this case, the distribution $F(x)$ is smaller than the distribution $\widetilde{F}(x)$ with respect to hazard order. ${ }^{17}$

To relate hazard-rate dominance to Lorenz dominance, we first note that in Une and Saijo (1995) it was shown that if there are two distributions on the same interval $[a, b]$, then the hazard-rate dominance of the first distribution over the second implies a first-order stochastic dominance of the first over the second. But first-order stochastic dominance implies second-order stochastic dominance, which we know from the work of Atkinson and Bourgignon (1989) to be equivalent to Generalised Lorenz dominance. So higher hazard rates are associated with both a higher level of non-compliance and However, the ratio of taxable profit to total profit fell from 60 to 30 percent in one year, as reported in Gurvitch (2002). This phenomenon is hard to explain using existing tax minimizing models. This paper provides a possible explanation - the key innovation being that we treat the price of tax reduction schemes as endogenous.

${ }^{17}$ See Muller and Dietrich (2002) for a further discussion on hazard rate ordering. 
a greater level of equality, at least as measured by the Generalised Lorenz dominance criterion. This is summarised in the following proposition.

Proposition 9 For any tax code $\tau(x)$ if the income distribution $F(x)$ hazard-rate dominates the distribution $\widetilde{F}(x)$, then $F(x)$ will exhibit both a higher level of tax non-compliance and a greater degree of equality as determined by the Generalised Lorenz dominance criterion.

Generalised Lorenz dominance is now equivalent to Lorenz dominance only if the means of the income distributions are the same. Although there is not such a close link between hazard rate dominance and Lorenz dominance, there is nevertheless a wide family of income distributions for which an increase in the variance will imply both an increase in inequality as measured by the Lorenz dominance criterion and a higher hazard rate and hence, from Proposition 8, a lower rate of tax non-compliance. Among these distributions are those commonly used in the literature for approximating actual distributions of income: e.g. Pareto distribution, Lognormal distribution and Exponential distribution. This is summarized in the following Proposition:

Proposition 10 For any tax code $\tau(x)$, if the income distribution $F(x)$ is either Pareto or Exponential, then an increase in the variance will result in both higher inequality in terms of Lorenz dominance and a lower hazard rate and hence, from Proposition 8, also a higher proportion of non-compliant taxpayers. The same conclusions hold for a mean preserving increase in variance for the Lognormal distribution.

Finally, we note that there is a link between the result of this sub-section and that of the previous sub-section. They both demonstrate that a more equal distribution of tax duties can lead to a greater level of non-compliance. In the previous section, the greater equality of tax duties was caused by a less progressive tax system whereas in this sub-section, the root cause is more equal distribution of pre-tax incomes. To formalise this idea, we need the following definition:

Definition 4 An increasing income transformation $y(x)$ equalizes tax burdens with respect to tax code $\tau(x)$ on interval $[a, b]$, if $\frac{\tau(y(x))}{\tau(x)}$ is decreasing on $(a, b)$. 
From the definition, any income transformation which equalizes tax burdens makes tax duties more equal according to the Lorenz ordering. The following proposition states that an income transformation which is equalizing with respect to tax code would reduce the share of compliant tax payers.

Proposition 11 Let $y(x)$ equalize tax burdens with respect to tax code $\tau(x)$. Then, if $k=0$, threshold equilibrium $\underline{y}^{e}$ is smaller than $y\left(\underline{x}^{e}\right)$, which implies a larger number of non-compliant taxpayers.

Proof. The relation between the old and new income distributions would be as follows: $F_{y}(z)=F\left(y^{-1}(z)\right)$, where $y^{-1}$ is an inverted function of $y$. We recall that $\underline{y}^{e}=\arg \max H_{y}(z)=[\tau(z)]^{1 / \chi}\left[1-F_{y}(z)\right]$. Substituting $x=y^{-1}(z)$, we obtain

$$
\begin{aligned}
{\underline{x_{y}}}^{e} & =\arg \max \tau(y(x))^{1 / \chi}(1-F(x)) \\
& =\arg \max H(x) g(x),
\end{aligned}
$$

where $\underline{x}_{\underline{y}}^{e}=y^{-1}\left(\underline{y}^{e}\right)$ and $g(x)=\left[\frac{\tau(y(x))}{\tau(x)}\right]^{1 / \chi}$. If $y(x)$ equalizes tax burdens, $g(x)$ is a decreasing function and we may apply Proposition 2 and conclude that $\underline{x}_{y}^{e}<\underline{x}^{e}$. This means that $\underline{y}^{e} \leq g\left(\underline{x}^{e}\right)$ and the share of non-compliant tax payers increases.

Proposition 11 proves that equalizing tax burdens with respect to tax income transformation may reduce the number of tax payers. For a simple proportional tax $\frac{\tau(y(x))}{\tau(x)}=\frac{y(x)}{x}$ and thus, there is a one-to-one link between the equality of pre-tax income i and the equality of tax burdens. Thus, increasing inequality as determined by the Lorenz dominance criterion may improve the indirect effect of tax compliance.

As a special case, consider the linear tax schedule $\tau(x)=t x-s, 0<t<1$ and suppose that we make the mean-preserving equalising transformation of income $y(x)=$ $\alpha x+(1-\alpha) \bar{x}, \quad 0<\alpha<1$. Then, the distribution of tax duties implied by this new distribution of pre-tax income is equivalent to that which would have been created had we alternatively introduced a new revenue-neutral tax reform to produce the tax schedule $\widetilde{\tau}(x)=\widetilde{t} x-\widetilde{s}, \quad$ where $\tilde{t}=\alpha t<t$ and $\widetilde{s}=s-t(1-\alpha) \bar{x}<s-$ which is a less progressive tax schedule. The implications for compliance can then be determined by applying Proposition 7.

In summary, our model predicts that pre-tax income inequality and tax compliance can be positively related. Similar conclusions have been obtained by Cowell (1992), albeit 
through a very different mechanism since in his model, inequality affects household utility through the costs of tax evasion.

In this section, we have shown how the degree of inequality of tax duties affects the level of compliance. In particular, we have shown that more equally distributed tax duties may reduce tax compliance. The inequality of tax duties can be related to both the distribution of pre-tax income and the progressivity of the tax schedule. In the next section, we show how the design of the penalty and monitoring functions can also affect the distribution of rewards to taxpayers from purchasing tax schemes and hence, the level of compliance. This implies that any changes in compliance created by shifts in the pre-tax distribution of income can be offset by changes in shapes of the penalty and/or monitoring functions.

\section{Two extensions}

\subsection{Monitoring, Punishment and Non-Compliance Technology}

So far, we have assumed that:

- schemes offer taxpayers the opportunity to save a fraction of their tax, $\beta$, which is independent of income, $x$;

- the probability that a scheme is subject to a successful challenge, $\pi$, is independent of income;

- the fraction of tax evaded that has to be paid as a penalty if a taxpayer's scheme, $\phi$, is effectively challenged is also independent of income.

In principle, each of these assumptions may be invalid.

- The opportunities for non-compliance may vary with income. While, in principle, this could go either way, it is likely that the greater is a taxpayer's income - and hence the greater the amount of tax due - the greater will be the opportunities for tax reduction. This suggests that an alternative assumption is that the fraction of tax saved by a scheme is an increasing function of income, $\beta^{\prime}(x)>0$. 
- The tax authorities can, in principle, choose how to deploy audit resources across different taxpayer groups and can thus choose a challenge schedule $\pi(x)$ that varies with income. Typically, they will target their audit resources more heavily on taxpayer groups which offer higher potential returns. Everything else equal, this would suggest that the monitoring function that is often used will be such that $\pi^{\prime}(x)>0$.

- In a similar spirit, the tax authorities may often negotiate settlements with taxpayers whereby they may not impose the full penalty $\phi$ that is legally available to them. For this and other reasons, we want to recognise that there is a de facto penalty schedule $\phi(x)>0$ that could vary with income.

For all these reasons, the expected net fraction of tax saved by purchasing a scheme is likely to vary with income - which we capture through the equation

$$
\alpha(x)=\beta(x)\{1-\pi(x)[1+\phi(x)]\} .
$$

It is then an immediate implication of Proposition 2 that, ceteris paribus, tax compliance is higher when the share of taxes saved grows with income at a faster rate. Formally, we have

Proposition 12 If $\widetilde{\alpha}(x)=\alpha(x) g(x)$, where $g^{\prime}(x)>0$ then $\underline{\widetilde{x}}^{e}>\underline{x}^{e}$ and $\widetilde{Q}^{e}<Q^{e}$.

Proof. Immediate application of Proposition 2.

This gives rise to three obvious corollaries.

Corollary 4 Ceteris paribus, the proportion of compliant tax payers is higher when the opportunities for tax saving, $\beta$, increase more rapidly with income.

As in some previous remarks, note that this does not imply that the tax gap will be smaller, since the higher percentage of compliant taxpayers is being offset by the fact that the non-compliant individuals are paying a smaller proportion of their taxes.

Corollaries 5 and 6 claim that the government can increase its tax collection by making monitoring and penalty functions more regressive, more frequently monitoring low income tax units and more heavily punishing them for tax evasion than the tax units with higher incomes. 
Corollary 5 Ceteris paribus, for income independent punishment $\phi\left(\phi^{\prime}=0\right)$, tax compliance is higher when the probability of audit is a more rapidly decreasing function of income, $\widetilde{\pi}^{\prime}>\pi^{\prime}$.

Proof. We can prove this by a direct differentiation of $g(x)$, where $g(x)=\frac{1-\widetilde{\pi}(x)[1+\phi]}{1-\pi(x)[1+\phi]}$ so that

$$
\frac{\partial(\log g)^{\prime}}{\partial x}=\frac{(1+\phi)\left(\tilde{\pi}^{\prime}-\pi^{\prime}\right)}{(1-\tilde{\pi}[1+\phi])(1-\pi[1+\phi])}>0
$$

Corollary 6 Ceteris paribus, for income independent audit probability $\pi\left(\pi^{\prime}=0\right)$, tax compliance is higher when the tax penalty is a more rapidly decreasing function of income, $\widetilde{\phi}^{\prime}>\phi^{\prime}$.

Proof. We can prove this by direct differentiation of $g(x)$, where $g(x)=\frac{1-\widetilde{\pi}(x)[1+\phi]}{1-\pi(x)[1+\phi]}$ so that

$$
\frac{\partial(\log g)^{\prime}}{\partial x}=\frac{\pi\left(\widetilde{\phi}^{\prime}-\phi^{\prime}\right)}{(1-\pi[1+\widetilde{\phi}])(1-\pi[1+\phi])}>0
$$

\subsection{Alternative pricing behaviour}

So far, we have assumed that sellers of a scheme are unable to observe the income of their clients and thus sell a scheme at a fixed price $p$ that takes the form of an up-front fee.

However, an alternative assumption might be that sellers can observe the taxable income of their clients, which opens up much richer pricing possibilities. For example, sellers may charge a combination of an up-front fee plus a share of the tax saved. But this raises the question of who bears the risk if the scheme fails and the taxpayer has to repay the tax and pay a penalty. Buyers might reasonably argue that if sellers take a share of the gains when their schemes work, they should also take a share of the cost when they fail to work.

Accordingly in what follows, we will assume that advisers make schemes available on a two-part tariff defined by $(p, \theta), p>0,0<\theta<1$, whereby the expected amount paid for a scheme by a taxpayer with income $x$ is $p(1-\theta)+\theta \alpha \tau(x)$. We can consider $p$ as an entry fee or a reserve price that must be paid by the taxpayer to purchase the scheme, and 
$\theta$ as the fraction of the expected gain ${ }^{18}$ (net the reserve price) from buying the scheme that the taxpayer must share with the seller. We will take $\theta$ as fixed and determined by exogenous factors that determine the (common) bargaining power between the buyer and the seller over how to share the gains from the scheme.

Bargaining is an extensively used model in the tax evasion literature, investigating the activities of a corrupt tax inspector who audits the individual's true income, but can be bribed into misreporting the audit result to the government. ${ }^{19}$ However, we believe the introduction of a reserve price to enrichen the model. The reserve price contract can easily be written, does not require any additional effort and, since the supplier can always set a zero reserve price, it increases the gain of the supplier. Finally, this type of contract is widely implemented as a wage contract for high-skilled professionals. A bargaining model with a reserve price was first introduced by Wang (1995).

We will continue to assume that all schemes are perfect substitutes and thus, in equilibrium, must be sold at the same entry fee, $p$. It is easily seen that an individual will buy a scheme iff

$$
\alpha \tau(x) \geq p
$$

\subsubsection{Aggregate Demand}

If $Q$ schemes are to be sold in aggregate then, as previously, the critical income that will create this will be $\underline{x}(Q)$ defined by $Q=1-F[\underline{x}(Q)]$, so that $\underline{x}^{\prime}(Q)=-\frac{1}{f^{\prime}[\underline{x}(Q)]}$. Consequently, the common entry fee consistent with selling $Q$ schemes in aggregate is $p(Q)=\alpha \tau(\underline{x}(Q))$. But then, the revenue earned by the scheme developer when $Q$ schemes are sold is

$$
R(Q)=(1-\theta) Q \alpha \tau(\underline{x}(Q))+\theta \int_{\underline{x}(Q)}^{b} \alpha \tau(x) f(x) d x,
$$

and thus, the marginal revenue is

$$
\begin{aligned}
R^{\prime}(Q) & =(1-\theta) \alpha \tau(\underline{x}(Q))-\frac{(1-\theta) \alpha \tau^{\prime}(\underline{x}(Q))}{f[\underline{x}(Q)]}+\theta \alpha \tau(\underline{x}(Q)) \\
& =\alpha \tau(\underline{x}(Q))-\frac{(1-\theta) \alpha \tau^{\prime}(\underline{x}(Q))}{f[\underline{x}(Q)]} .
\end{aligned}
$$

\footnotetext{
${ }^{18}$ Thus, sellers share with buyers both the gains from the schemes when they are successful and the losses when unsuccessful. That is, there is full risk sharing.

${ }^{19}$ See Chander and Wilde (1992) and Hindriks et al (1999).
} 


\subsubsection{Firm Behaviour}

As previously, the first-order condition for the revenue maximisation problem (18) is equivalent to the first-order condition of the problem

$$
x^{e}=\max (\arg \max H(x)),
$$

where we define

$$
H(x)=[\alpha \tau(x)]^{1-\theta}[1-F(x)]
$$

which is exactly the same as (13) except that the concentration parameter $\chi$ is replaced by the bargaining strength parameter $1-\theta$. We then have the following result, which is just a re-interpretation of Proposition 4.

Proposition 13 If the bargaining power of sellers increases, so will the proportion of non-compliant taxpayers.

However, there are reasons to believe that there is a significant market of tax evasion and avoidance schemes, where suppliers have a negligible bargaining power even in the absence of competition. In many cases, the value of the bribes paid to obtain tax exemption is significantly lower than the associated cost for the government budget. For example, in New York, according to the Gotham Gazette (2002), some 18 current and former city tax assessors accepted millions of dollars in bribes to improperly reduce the tax rates on at least 500 properties. Corruption costs the city as much as $\$ 1$ billion. The differences between the value of bribes and the amount of taxes not paid as a result are so huge that it may be difficult to assume any kind of bargaining. ${ }^{20}$

\section{Concluding remarks}

In this paper, we have modelled the tax advice industry which adjusts the supply of tax reduction schemes in response to changes in aggregate demand. Within this model, we

\footnotetext{
${ }^{20}$ Another potential illustration might be the Landfill tax scandal in the UK. According to The Guardian, a government appointed regulator, which polices the probity of $£ 280 \mathrm{~m}$ in tax credits given to thousands of UK environmental bodies, paid its directors over $£ 100,000$ in fees for two years without authorization.
} 
have shown how levels of compliance respond to a number of factors including the progressivity of the tax schedule and the distribution of taxable income. We have shown that it is extremely important to take this endogenous supply into account since it produces conclusions that run counter to much of the existing literature, but can also help explain phenomena that are otherwise hard to explain with existing models. For example, we have argued that a reduction in inequality or a decrease in tax progressiveness may result in a fall of the share of compliant taxpayers. Further, we have provided arguments against the reduction in the highest marginal tax rate as a policy directed at improving tax discipline.

We have also shown that when the government is reluctant to impose a more progressive tax code, it can still make tax evasion demand less equally distributed by designing a proper audit and punishment function. Finally, we have shown that our results are robust to the assumption on market structure, since they have been proved for Cournot game quantity competition with conjectural variation and a bargaining model with a reserve price.

A significant limitation of the model is the assumption that there is just one type of tax scheme. Ulph (2007) extends the model to the case with many tax schemes ranging from tax planning through tax avoidance to tax evasion, each with very different risk profiles and expected payoffs. However, in his model, there is perfect competition so prices are exogenous and determined by costs.

\section{Acknowledgements}

We would like to thank Charles Nolan, John Beath, Jim Jin, the editor and two anonymous referees for helpful comments and suggestions. Tatiana Damjanovic gratefully acknowledges financial support from the May Wong Smith Foundation.

\section{Appendix A. Proof of Proposition 2}

Proposition 2 Suppose $\widetilde{H}(x)=H(x) g(x)$ where $H(x)$ and $g(x)$ are positive, differentiable and $g^{\prime}(x)>0$. Suppose $\underline{x}^{e}=\arg \max H(x) ; \underline{\widetilde{x}}^{e}=\arg \max \widetilde{H}(x)$. Then $\underline{\widetilde{x}}^{e}>\underline{x}^{e}$.

Proof. Let us assume the contrary, $\underline{\widetilde{x}}^{e}<\underline{x}^{e}$. Since $g(x)$ is a strictly increasing function, it follows that

$$
g\left(\underline{x}^{e}\right)>g\left(\underline{\widetilde{x}}^{e}\right) .
$$


By definition, $\underline{\widetilde{x}}^{e}=\arg \max \widetilde{H}(x)$ and therefore

$$
\widetilde{H}\left(\underline{\widetilde{x}}^{e}\right)>\widetilde{H}\left(\underline{x}^{e}\right) .
$$

Inequalities (20) and (21) imply $\widetilde{H}\left(\underline{\widetilde{x}}^{e}\right) / g\left(\underline{\widetilde{x}}^{e}\right)>\widetilde{H}\left(\underline{x}^{e}\right) / g\left(\underline{x}^{e}\right)$, which is exactly as $H\left(\underline{\widetilde{x}}^{e}\right)>$ $H\left(\underline{x}^{e}\right)$, which is a contradiction since, by definition, $\underline{x}^{e}=\arg \max H(x)$. So the assumption is incorrect and $\underline{\widetilde{x}}^{e} \geqslant \underline{x}^{e}$. The equality is not possible either. Let $\underline{\widetilde{x}}^{e}=\underline{x}^{e}$. Then, $\widetilde{H}^{\prime}\left(\underline{x}^{e}\right)$ shall be equal to zero. However, $\widetilde{H}^{\prime}\left(\underline{x}^{e}\right)=H^{\prime}\left(\underline{x}^{e}\right) g\left(\underline{x}^{e}\right)+H\left(\underline{x}^{e}\right) g^{\prime}\left(\underline{x}^{e}\right)=H\left(\underline{x}^{e}\right) g^{\prime}\left(\underline{x}^{e}\right)>0$.

\section{References}

Anderson, F. J., 1977. Market Performance and Conjectural Variation. Southern Economic Journal 42, 173-178.

Anderson, S. P., Régis, R., 2003. Efficiency and Surplus Bounds in Cournot Competition. Journal of Economic Theory 113, 253-264.

Andreoni, J., Erard, B., Feinstein, J., 1998. Tax Compliance. Journal of Economic Literature XXXVI, 818-860.

Appelbaum, E., 1979. Testing Price-taking Behaviour. Journal of Econometric 9, 283-94.

Agell, J., Persson, M., 2000. Tax Arbitrage and Labor Supply. Journal of Public Economics 78, $3-24$.

Atkinson, A.B., 1970. On the Measurement of Inequality. Journal of Economic Theory $2,244-263$.

Åslund, A., 1999. Why Has Russia's Economic Transformation Been So Arduous? CERN WEB NOTE \#9.

Bassetto, M., Phelan C., 2008. Tax Riots. Review of Economic Studies 75 (3), 649669.

Baer, K., Silvani, C., 1997. Designing a Tax Administrative Reform Strategy: Experiences and Guidelines. IMF Working Paper 97/30.

Bergstrom, Th. C., Varian, H. R., 1985. Two remarks on Cournot Equilibria. Economics Letters 19, 5-8.

Borck, R., 2007. Voting, inequality and redistribution. Journal of Economic Surveys 21, 90-109.

Bresnahan, T., 1981. Duopoly models with consistent conjectures. American Economic Review 71, 934-45.

Le Breton, M., Moyes, P., Trannoy A., 1996. Inequality reducing properties of composite taxation. Journal of Economic Theory 69, 71-103.

Chander, P., Wilde L., 1992. Corruption in tax administration. Journal of Public Economics 49, 333-349.

Chander, P., Wilde L., 1998. A general characterization of optimal income tax enforcement. The Review of Economic Studies 65 (1), 165-183.

Coes, D. V., 1977. Firm output and charges in uncertainty. The American Economic Review 67 (2), 249-51.

Cowell, F. A., 1992. Tax evasion and inequality. Journal of Economic Psychology 13, 521-542. 
Damjanovic, T., 2001. The distributional component of the price for the tax avoidance service. Stockholm School of Economics Working Paper No 454.

Damjanovic, T., 2005. Lorenz dominance for transformed income distributions: a simple proof. Mathematical Social Sciences 50 (2), 234-237.

Desai, M. A., 2005. The degradation of reported corporate profits. The Journal of Economic Perspective 19, 171-192.

Desai, M. A., Foley, F. C., James R. H. Jr., 2006. The demand for tax haven operations. Journal of Public Economics 90, 513-531.

Erard, B. and Feinstein, J., 1994. Honesty and evasion in the tax compliance game. The RAND Journal of Economics 25, 1-19.

Erard, B., 1993. Taxation with representation: an analysis of the role of tax practitioners in tax compliance. Journal of Public Economics 52, 163-97.

Feinstein, J.S., 1991. An econometric analysis of income tax evasion and its detection. Rand Journal of Economics 22, 14-35.

Feldstein, M., 1999. Tax avoidance and the deadweight loss of the income tax. Review of Economics \& Statistics 81 (4), 674.

Financial Times, 2004, May 10, Shelters in the path of the shifting tax storm, by Amity Shlaes.

HM Revenue and Customs, 2007. Measuring indirect tax losses.

The Guardian, 2000, August 21, Landfill regulator under fees cloud, by David Hencke.

Gotham Gazette, 2002. April 15, Real property tax scandal, By Scott Stringer.

Gordon, J. P.F., 1989. Individual Morality and Reputation Costs as Deterrents to Tax Evasion. European Economic Review 33, 797-805.

Gurvitch, E., 2002. Taxes decrease but tax avoidance increases, an interview to Komsomolskaja pravda, in Russian.

Hindriks, J.; Keen, M.; Muthoo, A., 1999. Corruption, extortion and evasion, Journal of Public Economics 74, 395-430.

Internal Revenue Service, 2009. Abusive offshore tax avoidance schemes.

Internal Revenue Service, 2007. Reducing the Federal tax gap: a report on improving voluntary compliance. IR-2007-137, Aug. 2, 2007

Iwata, G., 1974. Measurement of conjectural variations in oligopoly. Econometrica 42 (5), 947-966.

Jakobsson, U., 1976, On the measurement of the degree of progression. Journal of Public Economics 5, 161-168.

Just, R., Chern W., 1980. Tomatoes, technology and oligopsony. Bell Journal of Economics 11 (2), 584-602.

Kakwani, N.C., 1977. Applications of Lorenz curves in economic analysis. Econometrica $45(3), 719-727$.

Kamien, M. I. ; Schwartz N. L., 1983. Conjectural variations, Canadian Journal of Economics 16 (2), 191-211.

Keen, M.; Papapanagos H., Shorrocks A., 2000. Tax reform and progressivity. Economic Journal 110, 50-69.

Kim, Y., 2003. Income distribution and equilibrium multiplicity in a stigma-based model of tax evasion. Journal of Public Economics 87, 1591-1616.

Kolstad C. D., Wolak F. A., 1986. Conjectural variation and the indeterminacy of duopolistic equilibria, Canadian Journal of Economics 19 (4), 656-77.

Laitner, J., 1980. "Rational" duopoly equilibria. Quarterly Journal of Economics 95, 641-62.R 
Lang, O., Nohrbas, K.-H., Stahl, K., 1997. On income tax avoidance: the case of Germany, Journal of Public Economics 66 (2), 327-347.

Muller, A., Dietrich S., 2002. Comparison Methods for Stochastic Models and Risks. Wiley Series in Probability and Statistics.

Myles, G. D., NaylorR. A., 1996. A model of tax evasion with group conformity and social customs. European Journal of Political Economy 12 (1), 49-66.

Pitt, M. M. and Slemrod J., 1989. The compliance cost of itemizing deductions: Evidence from individual tax returns. American Economic Review 79 (5), 1224-1232.

Reinganum, J., Wilde L. L., 1986. Equilibrium verification and reporting policies in a model of tax compliance. International Economic Review 27 (3), 739-760.

Robson, A., 1983. Existence of consistent conjectures: Comments. American Economic Review, 73 (3), 454-6.

Roine, J., 2006. The political economics of not paying taxes. Public Choice, 126(1), 107-134.

Rothschild, M., Stiglitz J., 1970. Increasing risk: I. A definition. Journal of Economic Theory 2, 225-243.

Sandmo, A., 1971. On the theory of the competitive firm under price uncertainty. American Economic Review 61, 65-73.

Scotchmer, S., 1987. Audit classes and tax enforcement policy. The American Economic Review 77, 229-234.

Shleifer, A., Vishny, R. W., 1993. Corruption. The Quarterly Journal of Economics 108 (3), 599-617.

Slemrod, J., 1995. Income creation or Income shifting? Behavioral responses to Tax Reform Act of 1986. American Economic Review 85 (2), 175-180.

Slemrod, J., 2001. A general model of the behavioral response to taxation. International Tax and Public Finance 8, 119-128.

Slemrod, J., 2004. The Economics of corporate tax selfishness, NBER Working Paper No. 10858.

Slemrod, J.; Yitzhaki, S., 2000. Tax Avoidance, Evasion, and Administration, NBER Working Paper No. 7473.

Tanzi, V., Zee, H. H., 2000. Tax Policy for emerging markets: Developing countries, National Tax Journal 53 (2), 299-328.

Torgler B., 2005, Tax morale in latin america, Public Choice 122 ,133-157.

Ulph, D., 1983, Rational conjectures in theory of oligopoly, International Journal of Industrial Organization 1, 131-54.

Ulph, D., 2008. Avoidance Policies -A New Conceptual Framework, (mimeo).

Wang, R., 1995. Bargaining versus posted-price selling. European Economic Review 39, 1747-64.

Yitzhaki, S., 1974. A note on 'Income tax evasion: A theoretical analysis'. Journal of Public Economics 3, 201-202.

Yaniv, G., 1990, Tax evasion under differential taxation, Journal of Public Economics $43,327-337$. 


\section{OXford University Centre for Business TAXation WORKING PAPER SERIES}

WP09/28 Damjanovic, Tatiana and David Ulph, Tax Progressivity, Income Distribution and Tax Non-Compliance

WP09/27 Grubert, Harry, MNC Dividends, Tax Holidays and the Burden of the Repatriation Tax: Recent Evidence

WP09/26 Grubert, Harry, Foreign Taxes, Domestic Income, and the Jump in the Share of Multinational Company Income Abroad

WP09/25 Maffini, Giorgia, Tax Haven Activities and the Tax Liabilities of Multinational Groups

WP09/24 Bach,Laurent and Nicolas Serrano-Velarde, The Power of Dynastic Commitment

WP09/23 Dischinger, Matthias and Nadine Riedel, There's No Place Like Home: The Profitability Gap between Headquarters and their Foreign Subsidiaries

WP09/22 Ulph, David, Avoidance Policies - A New Conceptual Framework

WP09/21 Ulph, Alistair and David Ulph, Optimal Climate Change Policies When Governments Cannot Commit

WP09/20 Maffini, Giorgia and Socrates Mokkas, Profit-Shifting and Measured Productivity of Multinational Firms

WP09/19 Devereux, Michael P., Taxing Risky Investment

WP09/18 Buettner, Thiess and Georg Wamser, Internal Debt and Multinationals' Profit Shifting - Empirical Evidence from Firm-Level Panel Data

WP09/17 Arulampalam, Wiji, Devereux, Michael P. and Giorgia Maffini, The Direct Incidence of Corporate Income Tax on Wages

WP09/16 Keuschnigg, Christian and Evelyn Ribi, Profit Taxation and Finance Constraints

WP09/15 Shaviro, Daniel N., Planning and Policy Issues raised by the Structure of the U.S. International Tax Rules

WP09/14 Karkinsky, Tom and Nadine Riedel, Corporate Taxation and the Choice of Patent Location within Multinational Firms

WP09/13 Koh, Hyun-Ju and Nadine Riedel, Assessing the Localization Pattern of German Manufacturing \& Service Industries - A Distance Based Approach 
WP09/12 Loretz, Simon and Padraig J. Moore, Corporate Tax Competition between Firms

WP09/11 Desai, Mihir A. and Dhammika Dharmapala, Dividend Taxes and International Portfolio Choice

WP09/10 Devereux, Michael P. and Christian Keuschnigg, The Distorting Arm's Length Principle

WP09/09 de la Feria, Rita and Ben Lockwood, Opting for Opting-in? An Evaluation of the Commission's Proposals for Reforming VAT for Financial Services

WP09/08 Egger, Peter, Keuschnigg, Christian and Hannes Winner, Incorporation and Taxation: Theory and Firm-level Evidence

WP09/07 Becker, Johannes and Clemens Fuest, Optimal Tax Policy when Firms are Internationally Mobile

WP09/06 de la Feria, Rita, Place Where the Supply/Activity is Effectively Carried Out as an Allocation Rule: VAT vs. Direct Taxation

WP09/05 Loomer, Geoffrey T., Tax Treaty Abuse: Is Canada responding effectively?

WP09/04 Egger, Peter, Loretz, Simon, Pfaffermayr, Michael and Hannes Winner, Corporate Taxation and Multinational Activity

WP09/03 Simpson, Helen, Investment abroad and adjustment at home: evidence from UK multinational firms

WP09/02 Becker, Johannes and Clemens Fuest, EU Regional Policy and Tax Competition

WP09/01 Altshuler, Rosanne and Harry Grubert, Formula Apportionment: Is it better than the current system and are there better alternatives?

WP08/30 Davies, Ronald B. and Johannes Voget, Tax Competition in an Expanding European Union

WP08/29 Pfaffermayr, Michael, Stöckl, Matthias and Hannes Winner, Capital Structure, Corporate Taxation and Firm Age

WP08/28 Desai, Mihir A. and Dhammika Dharmapala, Taxes, Institutions and Foreign Diversification Opportunities

WP08/27 Buettner, Thiess, Riedel, Nadine and Marco Runkel, Strategic Consolidation under Formula Apportionment

WP08/26 Huizinga, Harry, Voget, Johannes and Wolf Wagner, International Taxation and Takeover Premiums in Cross-border M\&As

WP08/25 Barrios, Salvador, Huizinga, Harry, Laeven, Luc and Gaëtan Nicodème, International Taxation and Multinational Firm Location Decisions 